\title{
The political ecology of weeds: a scalar approach to landscape transformations
}

\author{
Christian A. Kull and Haripriya Rangan
}

Authors' version. Final definitive version of chapter published in:

Kull, CA \& H Rangan (2015) The political ecology of weeds: a scalar approach to landscape transformation. In The International Handbook of Political Ecology, edited by Bryant, RL. Cheltenham: Edward Elgar, 487-500.

https://www.elgaronline.com/view/9780857936165.xml

'Think globally, act locally' says the green maxim. Yet, when applied to plants labelled
'weeds' or 'invasive', this idea suggests a scalar mismatch. At the global level, invasive
species are often listed alongside the biodiversity crisis and climate change as top
environmental concerns with enormous economic ramifications. At the local level, any
farmer or gardener will share the common human experience of intimate, sensory
interactions with weeds - considering, touching, pulling, perhaps spraying. The global
scale is dominated by lists, categories and costs; the local by praxis, need and emotion.
The global is scientific and bureaucratic; the local is lived and pragmatic. There is a
wealth of difference between and within these levels of scale - differences of power,
perception and of geographical distribution; in short, a 'political ecology' of weeds that
we review in this chapter. What interests us, as political ecologists of weeds, is when
and how the quotidian movements of plants and processes of ecological and attendant
social change - that is, their occurrence and spread across landscapes - become
phenomena characterized as weeds or weed invasions and thereby objects of contention
and control.

Our political ecology perspective goes beyond discursive critiques of the language of weeds and invasion, beyond the dichotomization of weed issues into conflicts of interest between, for instance, the livelihoods of farmers and the biodiversity goals of conservationists. We refocus the lens at an intermediate scale, making regional landscapes the unit of analysis, instead of crop fields, plant species, ideologies or interest groups. Without going into details of the rich geographical literature on concepts of landscape, we use the term as a reference to distinct associations of physical and cultural forms (in a Sauerian sense) and as relational perceptions of these associations through classification, control, meaning and symbolism (Cosgrove, 1998). This analytic scope allows us to investigate how weeds, invasives and other mobile plants are interpreted, managed, accepted, controlled or reacted to in the broader geographical context of living and transforming regions.

In order to understand how plants become 'weeds' and 'invasives' in landscapes, we rely on a scalar analytic framework based on a Lefebvrian understanding of the production of space (Rangan and Kull, 2009). We suggest that there are three scalar moments that interact to produce lived, conceived and contested landscapes. First, the operational scale relates to empirical phenomena in nature and society. Second, the observational scale relates to formalized human conceptions of these phenomena, and the power they exert, at different levels of scale. Third, the interpretive scale opens up the world of stories, moralities and sensibilities by which humans communicate and express their feelings or concerns regarding the phenomena around them. 
In the following sections, after expanding on our scalar approach, we use these three moments of production of scale to show how plants become weeds and how they are subjected to categorization and targeting in different spatiotemporal and socioecological landscapes. While there are innumerable examples available, we have limited ourselves to using case studies of three plants to illustrate how this process occurs. These plants are Lantana camara (lantana), the genus Acacia (common names ranging from acacia or wattle to huisache or mimosa) and Ambrosia artemisifolia (ragweed).

\section{POLITICAL ECOLOGY OF SCALE}

In an earlier paper (Rangan and Kull, 2009), we argued that scale is the means through which ecological and related social and economic changes are made political. We adapted Henri Lefebvre's (1974) ideas about the 'production of space' to understand how scale, a critical component of spatiotemporal analysis, is not a pre-given dimension, but produced through activity. Lefebvre describes the production of space as embracing three kinds of actions. First, spatial practice refers to the physical activities and patterns of interaction that people engage in as a matter of routine. They take this space for granted because it is what they 'perceive' and what they have to negotiate through the activities and movements of everyday life. Second, representations of space are produced by dominant social actors - scientists, planners, urbanists, artists - who categorize, organize and conceptualize spatial practice according to what they think it should be in order to exercise control. Third, representational space is consciously performed by people through images and symbols, embracing 'the loci of passion, of action and of lived situations' and it 'may be directional, situational or relational, because it is essentially qualitative, fluid and dynamic' (Lefebvre, 1974: 41-2). These moments come together through activities and movements to produce space as practices of everyday life, as measures or categories of spatial difference, and the means for engaging in political action.

Following Lefebvre's reasoning, we proposed that scale is produced by three moments of action: operation (an ontological moment), observation (an epistemological moment) and interpretation (a translational moment). First, operational scale is produced from combinations of time, space and power that shape social activity and biophysical processes into particular configurations. It is ontological and empirical, based on inductive knowledge and description of features, processes or phenomena. Second, observational scale is produced through measurement and control by governments, policymakers and researchers. Because study or surveillance depends on establishing 'objective' categories, and resolutions of spatiotemporal limits, it is often the subject of contention in scientific and policy debates.

Finally, interpretive scale is produced through translation of phenomena into narratives, 'models', metaphors or tropes in ways that imbue significance and symbolic meaning. It produces a normative hierarchy of values that serves as the context and means by which extrapolation, generalization and simplification occur (Foucault, 1980).

For instance, models and symbols signify various ecological phenomena and entities as good, bad, useful, native, alien, benign or invasive. Interpretive scale plays a critical 
role in making social and ecological change political by invoking feelings of belonging, taste, beauty, usefulness, fear or hope.

This mode of understanding the production of scale enables us to move beyond mainstream representations of weeds and critiques of such representations, and instead focus on how particular plants, with their characteristics and behaviours, come to be regarded as weeds or invasive species in different spatiotemporal contexts. While much of the discussion regarding weeds swings in bipolar fashion between global threats and locally disastrous consequences, our scalar approach allows a broader politicalecological perspective that views how particular plants and their spatiotemporal interactions with human activity are implicated in the transformation of landscapes.

\section{OPERATIONAL SCALE}

From an operational scale perspective, plant movements can be seen to occur through dispersal, disturbance, transfer and diffusion (Kull and Rangan, 2008). Each kind of movement encompasses distinctive combinations of scales and agents. Dispersal by wind, water and non-human agents such as insects, birds and animals generally covers shorter distances, but can cumulatively affect large areas over long periods. Disturbances such as fires, floods, erosion or vegetation clearance, whether 'natural' or anthropogenic, can create conditions for plants propagating across large or small areas, depending on the frequency with which they occur. We reserve the term 'transfers' for long-distance movements - across land and oceans - of plant genetic material by humans in their various capacities as traders, naturalists or agricultural scientists. Transferred plants may be limited to gardens, hothouses or agricultural research stations, or they may have larger impacts at the landscape scale over several decades through subsequent dispersal, disturbance or diffusion. By diffusion, we refer to the purposive spread of plants from person to person (Sauer, 1969), between individual farmers and gardeners, and through agents such as government agricultural extension workers, forestry companies, development agencies and commercial nurseries.

These processes take on different levels of importance at varying analytic scales. A geological perspective reveals that plants have responded to changes in their climate and environment through movement and adaptation since their emergence on land in the Palaeozoic Era. The land on which they grow has been transformed by continental drift, orogeny, volcanism, erosion; climatic conditions have fluctuated between warm and cool, wet and dry; vegetation cover and soils have been disturbed by storms and quakes; and plant parts or seeds have been dispersed by insects, animals, birds, water and wind, over both short and long distances (Brown and Sax, 2004). Despite the appearance today of plants being part of long-term stable ecosystems, their spatiotemporal distribution has been in constant flux.

Humans have also been effective dispersal agents for a long time (McNeill, 2003; Wilson et al., 2009). Examples include the spread of Livistona palms and of baobabs through the Pleistocene and Holocene (Kondo et al., 2012; Rangan et al., 2015). Ancient oceanic exchanges extending back six millennia enabled long-distance plant transfers and diffusions (Rangan et al., 2012). The emergence of settled agriculture and animal husbandry not only led people to select and move plants to different places for 
cultivation, but also to establish relationships between cultivated and uncultivated plants in situ. These activities created the spatial contexts for various plants to be identified as wanted or unwanted (Harlan and de Wet, 1965).

The transfer and diffusion of plants gained substantial momentum over the past millennium with the expansion of human populations and increased overland and oceanic exchanges and trade. Settler conquest and colonialism in the Americas and Australasia combined purposive transfer and diffusion with accidental, unplanned movements of plants and organisms and large-scale disturbances that contributed to large-scale landscape transformations in their new environments within short time periods (Crosby, 1986). The rise of industrialization and demand for large-scale production of raw material in Europe led to further intensification of plant transfers for cultivation in territories under European colonial rule in Africa and Asia (Brockway, 1979), and the exponential growth of global trade in the past 150 years has been paralleled by the growth in the movement of plant genetic material.

Let's look at our exemplar plants from the perspective of operational scale. The broad genus Acacia (which contains more than a thousand species, including the thorn trees of Africa, wattles of Australia and huisache of the Americas) has long been dispersed by birds, ants, grazing animals and other natural forces; prehistoric people who consumed seeds certainly contributed to these movements. In the last 500 years, several dozen species of Acacia have been transferred across oceans by botanists, traders, settlers and administrators, with a significant increase during the nineteenth and twentieth centuries by foresters, garden enthusiasts and agroforestry development projects. Local and regional diffusion occurred as people sought the trees for diverse uses, including leather tanning, perfume distillation, livestock shade or fodder, fuel production, land rehabilitation and ornamental cultivation. Most acacia species produce an abundance of dispersible seeds that can remain viable in the soil for decades, and respond favourably to disturbance such as fire or tilling. Given their capability for vigorous expansion, these transferred acacia species can dominate landscapes (Kull and Rangan, 2008; Richardson et al., 2011).

Lantana camara is an erect flowering shrub with spreading, prickled branches. Originally from the Americas, it has been transferred to and diffused around most tropical and sub-tropical regions of the world. This largely occurred during the nineteenth century, at the height of European colonial expansion, when its ability to flower with a rich variety of colour throughout the year led to its widespread popularity as an ornamental plant. Lantana thrives in gardens as well as in open, disturbed habitats where its roots spread and sucker vigorously. It produces abundant small fruit that are eaten and dispersed by birds. These characteristics have resulted in lantana establishing itself rapidly across urban and rural landscapes, in vacant lots, fallows, field edges and uncultivated open lands. It can be toxic to cattle and physically difficult to contain or remove from farmland (Thaman, 1974; Kannan et al., 2013, McWilliam, 2000).

Our third exemplar, ragweed (Ambrosia artemisiifolia), is an herbaceous member of the aster family, native to the Americas. It thrives in disturbed soils and produces copious amounts of pollen that is easily windborne and attracts insects that help its dispersal across urban and rural landscapes. These characteristics have led it to become known as a prominent cause of human hay fever allergies. The plant has been noted in Europe since the mid-1800s, through numerous arrivals in diverse locations in 
shipments of grain, fodder and birdseed. Over the past few decades, the plant has expanded in certain parts of Europe through inadvertent human diffusion, contributing to the growth of allergies in its new home. The plant is frequently targeted for control or removal from gardens and disturbed sites using chemical herbicides (Mitman, 2004; Brandes and Nitzche, 2006; Chauvel et al., 2006; Fall, 2013).

In sum, at the operational scale, the characteristics and behaviour of each plant are intimately entwined with human movement and activity. Their patterns of occurrence and spread are influenced in part by physical forces, soil conditions and nonhuman agents, but more strongly by humans, who are the key agents of landscape transformation. As Harlan and de Wet (1965: 19) commented in their classic essay, 'there can be no weeds in the absence of man'. They point out that numerous plants rely and thrive on human disturbance of landscapes. Some of these are domesticates that humans choose to grow, while others are plants that thrive alongside without the attention and care that domesticates receive. The operational scale, therefore, reveals what Harlan and de Wet felicitously call the 'biologically intimate' (ibid.) relationship between humans and weeds: they accompany humans wherever they go and prosper in landscapes that humans modify. The biologically intimate relationship is reflected in the wide range of human interactions with these plants, whether in consuming and using them, in seeing and smelling them or in labouring to cut them back, dig them out or spray them with chemicals (Awanyo, 2001; Robbins, 2007; Atchison and Head, 2013).

\section{OBSERVATIONAL SCALE}

Observational scale refers to the formalized ways of classifying and measuring a phenomenon. While operational scale can yield forms of classification and description of phenomena in terms of patterns, interactions and processes, these do not have power until they are recognized and legitimized by formal authority, whether government officials or scientists. In effect, observational categories are produced by the application of instrumental or institutional rationality - geopolitical, economic, social - for purposes of governance or maintaining order and control. The result, in the case of weeds, is a scalar jump from 'weed' as a contextual, field-based relational perception by people-in-landscapes, to 'Weed-with-a-capital-W' as a powerful bureaucratic category. A plant out of place in a particular field becomes a plant out of place in a whole landscape, region or even continent. And, conceptually, a plant that is judged on its merits (or demerits) in place is instead judged to have those merits (or demerits) intrinsically. A plant that would be considered annoying but tolerated becomes a biological entity that should be controlled and possibly exterminated.

Foucault's concept of 'biopower' is helpful in understanding how observational scale operates. Biopower represents the techniques, technologies and discourses used by governing bodies to monitor, control and manage human lives and bodies within their jurisdictions. It entails one or more truth discourses about the characteristics that categorize populations as 'normal' and also establishes different categories that mark deviance from the normal (Rabinow and Rose, 2006: 195, 197). Foucauldian biopower is exercised by authorities (such as demographers, criminologists, doctors, health 
officials and psychologists) considered competent to speak truth discourses and to develop strategies for intervening in and governing the lives of people in accordance with their population categories. These population categories also act as selfdisciplining mechanisms for individuals who accept such subjectification of, and interventions in, their lives in the name of collective good, public health or societal order. Biopower is thus a rationalizing mode of governance explicitly linked to discourses and apparatuses of security and surveillance. The recent emergence of the term 'biosecurity' (Elden, 2007; Bingham et al., 2008; Braun, 2011; Dobson et al., 2013) with respect to territorial border control is a literal reference to the exercise of biopower over the entry of humans and non-human organisms by national governments.

While weeds, from an operational scale perspective, are plants not purposefully cultivated but which appear in places of human disturbance, their conceptualization as 'plants out of place' is an observational scale categorization linked to the exercise of biopower. The observational scale is established in relation to institutional jurisdictions and spatial categories based on instrumental rationalities associated with agricultural production, public health or prevention of plant diseases (quarantine), or protection of landscapes and vegetation with uniquely 'national' or 'native' qualities (biodiversity). So, for instance, a plant that is pulled out from a garden or field so that another plant can grow may be categorized as an 'noxious weed' if it spreads into a landscape that is used by livestock or forestry industries, or as an 'alien invasive' plant if viewed from national biodiversity management goals. These 'jumps' of observational scale permit and condition the exercise of power by national and global networks of policy-makers, researchers, conservationists and quarantine agents.

The formal categorization of weeds through the exercise of institutional and instrumental rationality by governments - in terms of national public health, economic productivity or territorial identity (native or otherwise) - has a relatively short history. Western governments began establishing agricultural services for farmers engaged in commercial crop production in the nineteenth century, and by the turn of the twentieth century agronomy developed into a university discipline. Pioneers such as Wilfred Robbins and Alden Crafts at the University of California, Davis initiated a separate formal 'weed science', publishing the first edition of a field-defining textbook in 1942 (Zimdahl, 2010). They presented clear categories of weed types and control strategies that resonate in agronomic bureaucracies to this day. Weed services and weed science boomed after the development and large-scale production of chemical herbicides in the postwar period (Timmons, 1970; Tilman et al., 2001).

The categorization of weeds as 'alien invasives' or 'environmental weeds' is far more recent, and reflects a rise in environmental concern for ecosystem balance, health and function. Invasion biology has eclipsed older agronomic weed science. Indeed, in 1982 the 'SCOPE 37' research programme of the International Council of Scientific Unions, a major catalyst for growth in this field, stated that its aim was to 'build on the considerable knowledge base available on invaders of agricultural systems but that it should concentrate its efforts on natural systems where there had been considerably less attention' (Drake et al., 1989: xxiii). The now prolific field of invasion biology investigates the factors that enable certain species to spread across geographic and ecological barriers and their impacts on ecosystems and economies (Cronk and Fuller, 1995; Davis, 2009; Richardson, 2011). The field justifies its importance through 
instrumental metrics. Pejchar and Mooney (2009: 497) call the impacts of invasives on ecosystems 'staggering . . . but largely anecdotal and wide ranging'. Yet this has not deterred people from estimating their economic costs (e.g. Pimentel et al., 2005); one estimate from South Africa blamed invasive trees for a 40 per cent loss of potential economic value from the land (MEA, 2005: 57).

Invasion biology, as a global field, has major influence on the conceptualization of weeds and their importance. It plays a key role in establishing the 'truth discourse' of categories, definitions and facts about invasive species that are then applied to land management policies and actions. As is to be expected in any 'truth discourse', definitions - of invasives, environmental weeds, natives, aliens and so on - attempt to be universal in principle but are rarely so in reality (Colautti and MacIsaac, 2004; Richardson et al., 2008; Blackburn et al., 2011; Humair et al., 2014). Overall, though, the definitions put forward seek to define invasive plants by combining one or more of three characteristics: origin, behaviour and impact. Origin refers to a plant's alien status; behaviour is the actual (or potential) extensive and rapid spread of reproductive offspring away from transported parent plants; and impact refers to actual (or anticipated) negative effects on native ecosystems or human health, society or economic activity.

The formal categories and classification of plants as 'invasive' shifts the observational scale from contextual, field- or landscape-based perceptions to more abstract, categorical and territorial ones. Furthermore, most definitions of invasives largely exclude the role of human activity and its collusion in assisting invasions by particular plants, particularly through disturbance. Also, while any ecologist will clarify that it is populations of a particular species that are invasive, not the species itself, the epithet inevitably sticks to the latter.

The rise of invasion biology as a 'global' science has driven the development of international and national lists of invasive species and associated management policies. Despite the uncomfortable fit of weed control with anxieties over food safety, epidemics and pests (Bingham et al., 2008), the discourse of invasive species has led to many government agencies dealing with agricultural weeds being subsumed or replaced by biosecurity agencies (Barker, 2008). The impact of lists of invasive species made available through a variety of online databases is that a number of plants have gained the label 'invasive' (which is equivalent to being labelled 'terrorist' by national security agencies), irrespective of context. The categorization of invasive, particularly in terms of status of origin, carries great power. A genetic study of a diminutive clover fern in the Azores by Schaefer et al. (2011) showed that it was not a rare native species but an Australian alien. This resulted in a change in the plant's status from the archipelago's highest conservation priority native species to an alien invasive whose further spread had to be prevented.

Our exemplar plants have all been formally categorized as noxious weeds and invasive aliens. Lantana camara carries these labels in most places where it has been introduced. Its widespread presence and its nuisance to agriculture and pastoralism placed it early on global lists of weeds and invaders (Thaman, 1974; Holm et al., 1977; Cronk and Fuller, 1995). Acacia species rank high on many national lists of invasive trees and shrubs. In South Africa, nine Australian acacias are legally declared as 
'major' invasives that must be controlled or eradicated where possible. While commercially important species such as Acacia mearnsii may be cultivated, their presence outside plantations is categorized as invasive and they are targeted for removal in 'priority zones' such as watersheds or ecosystems of 'national or international significance'. In Australia, the prickly acacia, Acacia nilotica, is a Weed of National Significance, with dedicated strategic plans, management guides and containment zones similar to those in South Africa (Kull and Rangan, 2008). Ambrosia is listed as one of the most important invasive plant species in France (Chauvel et al., 2006), and is blamed for health impacts totalling $€ 32$ billion per year in Germany (Brandes and Nitzche, 2006). Its presence in Switzerland even influenced the development of a national list of invasive plants; in the 2006 Vegetation Protection Act it is the only species listed under the category "Particularly dangerous weeds". While Swiss authorities initially classified plants as invasive based on biodiversity threat criteria, the event of a growing ragweed invasion led to strong political pressure for the inclusion of economic and public health criteria (Fall, 2013: 170).

In sum, at the observational scale, formal categorizations, based on instrumental rationalities and truth discourses produced in certain scientific-bureaucratic circles, aim to police the territorial boundaries of plant movement. Yet, of course, the observational interacts with the operational and interpretive scales in shaping and transforming particular landscapes. As the Swiss example above suggests, practice and politics push back against rigid truth discourses. Barker (2008: 1612) corroborates this in New Zealand, showing that biosecurity practices 'produce a complexity of semipermeable control boundaries that are flexible and sensitive to the shifting spatiotemporal geographies of indeterminate entities, and to changing and competing human values'.

\section{INTERPRETIVE SCALE}

Observational categories laden with biopower inevitably rub up against cumulative empirical, relational and interpretive phenomena. The interpretive moment manifests itself in the stories, moralities and sensibilities by which people communicate and make sense of the phenomenon of plants that spread vigorously across space. Their ideas and feelings about weeds and invasives are often a mix of pragmatic experience and 'stories' told by friends, family, scientists and officials. By stories, we refer to Foucauldian discourses that draw on archetypes to bolster their rhetorical claims to genuine or just representations. What is of interest is how people use these archetypal narratives to convey their concerns and emotions about the plants in their landscapes, how they accept, question or challenge the observational categories and management actions of scientists and policy-makers. Some may incorporate the 'truth discourses' of scientists into their narratives; others may acknowledge the scientists' views on plants but dismiss them for various reasons; and yet others may present alternative or contrasting views about the plants. Such discourses and their normative hierarchies of value become the translational moment for plants to become 'invaders', 'saviours' or 'fellow travellers', generating argument, debate or acts of resistance against authority.

The topic of weeds has generated different kinds of metaphors that deploy varying interpretive scales for narrating the 'impacts' and 'affect' of invasive species on people 
and societies (Larson, 2011; Warren, 2007; Tassin and Kull, 2012). Most of these metaphors rely on conveying these impacts by invoking some combination of values and concerns related to utility, aesthetics, personal costs, socio-spatial identity or survival of life. To give a few examples: a number of agroforestry species have been described as 'miracle plants', providing extraordinary and transformative benefits for utility and well-being in the places where they were introduced; alternatively, other narratives may describe the same plants as 'destroyers' that undermine agriculture and the utility and well-being of farmers. The acclimatization movements of the late nineteenth and early twentieth centuries in European settler colonies like Australia, Algeria, South Africa and Palestine used the metaphor of 'improvement' of unfamiliar and seemingly unaesthetic and unproductive landscapes to justify the introduction of plants and animals from various parts of the world (Osborne, 2000; Tyrrell, 1999). A metaphor that appeals to aesthetics of uniqueness may also be evoked to justify the creation or protection of a territorially based identity. This often appears in claims made by invasion biologists about the effects that alien plants have on unique ecosystems, and how they represent 'a human-caused breakdown of the regional distinctiveness of Earth's flora and fauna' (Vitousek et al., 1997: 1). Some use metaphors such as 'McDonaldization' or 'biotic homogenization' to describe the effects of introduced species on regional landscapes (McKinney and Lockwood, 1999).

Then, of course, there is the most compelling metaphor of all, that of invasion and extinction. As Seddon (2005: 223) notes, 'the language [of weeds] is powerfully emotive. "Invasive" is a word alive with threat, and "infestation" suggests the plague and the urgent need for a pied piper to lead the invading rats to their destruction'. Charles Elton used this metaphor with compelling effect in conveying the threat of introduced plants and animals as equivalent to a wartime invasion and occupation of Britain. Metaphors of national defence and national identity were used in very dramatic or stark ways to influence social perceptions of plants in the first half of the twentieth century in Germany (Gröning and Wolschke-Bulmahn, 2003), as well as in the long 'historical preoccupation of (mainly white) South Africans with non-native plant species' (Neely, 2010: 871). Although there is now a well-trodden critique of the militaristic, epidemiological, nativist or even xenophobic vocabulary used to build up anxieties about weeds and invasives, by both social and natural scientists (Gould, 1997; Colautti and MacIsaac, 2004; Head and Muir, 2004; Warren, 2007; Davis, 2009), the metaphors of invasion and extinction continue to be the most popular among scientists and national park and landscape management agencies.

The discourses that frame the translational moment differ over time and space in concordance with social context, pragmatic experience and positionality. For instance, views of German forest managers towards the vigorously spreading American black cherry varied over time, initially based on their hopes for timber or soil improvement, later on their fears about invasion, and then on their hopes for feasible control. These discourses were more aspirational than based on fact, but strongly influenced forestry practices (Starfinger et al., 2003). Villagers in southern Madagascar draw on memories and stories of a prickly pear cactus eradication campaign and a famine that followed it to interpret contemporary experiences of a recent campaign against prickly pear by conservation and development agencies, and 're-narrate' the invasion story and the morals associated with it (Middleton, 2012). 
As for our exemplars, the story of Lantana in Timor shows how interpretations shift based on different discursive framings (McWilliam, 2000). At the peak of the plant's spread during the 1940s and 1950s, foresters defended lantana as a host or nurse plant for sandalwood, while cattle owners decried its unpalatable nature and expansion into grazing lands. Farmers were more equivocal, balancing increased labour requirements against beneficial soil impacts and firewood supply. Similarly, Mitman (2004) shows how Ambrosia - as a weed of disturbed areas, empty lots and railway corridors in its native land America - was painted differently according to the varied social discourses of each period - as a troublesome vagrant, as a symptom of moral depravity associated with modernity, or as a medicalized hay fever threat.

Different interpretive scales operate not only across historical time, but simultaneously among different people. In the case of Ambrosia in Switzerland, Fall (2013) shows how expert categories are renegotiated and transgressed through differing interpretive scales. She notes that, although environmental managers were loyal to the cause of fighting invasives, they justified not taking action in many specific cases due to personal judgements that a particular plant was not a problem, due to time or money constraints, or by referring to aesthetic or public opinion in favour of the plant. A similar example arises with differing attitudes towards the presence of prickly acacia (Acacia nilotica) in Outback Queensland. Rangan et al. (2014) show how pastoralists fall into different groups based on the metaphors they use to view and manage this species on their properties. The 'pragmatists' echo the 'war against weeds' discourse commonly used by government agencies, and draw on their financial support to deploy bulldozers and chemicals to eradicate the plants. The 'unsuccessful battlers' criticize the impracticality and ever-changing nature of government agency advice and policy, and speak largely of disheartenment in the face of an unsolvable problem. The 'strategists' talk of accepting the land as it is and managing the dynamic relations among cattle, grass, soil and prickly acacia from the perspective of 'doing right by country'.

\section{WEEDS AND THE POLITICAL ECOLOGY OF LANDSCAPE TRANSFORMATION}

In any particular place and time, the processes and patterns linked to the three scalar moments - operational, observational and interpretive - interact to produce their own distinctive landscapes. Biophysical and socio-cultural processes of daily life interact with powerful formal categorizations as well as emotive and normative stories and interpretations, shaping landscapes and how they are seen. The analysis of these scalar moments and their coming together produces a political ecology of landscape transformation. This chapter shows how this approach can help in understanding how the intertwined social and ecological phenomena of plants in movement come to matter and inspire so much research, public concern, anxiety, chemical use and contestation.

Plant movements, and indeed human movements, can be viewed through different 'scopes', such as disruption, transformation and evolution (Rangan and Kull, 2009). Most invasion biology and political ecology studies focus on immediate spatiotemporal consequences such as disruption to places, human communities or native biodiversity. 
Some authors use different metaphors to talk about changes in plant communities, such as 'novel ecosystems' (Hobbs et al., 2006), 'rambunctious gardens' (Marris, 2011) or 'melting pots' (Kull et al., 2013), to emphasize different forms of transformation. Others describe these processes as regionalized evolution (Botkin, 2012; Rangan et al., 2012).

It is important that political ecologists and invasion biologists can adopt scopes of analysis that encompass landscape and ecological change as an integral part of the human processes of regional transformation and evolution. A good example might be the work of McWilliam (2000), who recounts three major plant invasions that have succeeded each other over the last century in the beef-producing grazing lands of Timor: first prickly pear (Opuntia), then Lantana camara, then Chromolaena odorata. Combining a historical perspective with a sympathetic understanding of peasant farmers' attitudes of adaptation, McWilliam is able to tell the story with a broader, noncatastrophic scope. He mentions that, while Indonesian government pastoral officials, with Australian technical support, sought to control the weeds, most other agencies were ambivalent or positive about the plants, leading to an overall laissez-faire approach. He notes that the responses of the subsistence-oriented farmers and of many local officials 'tend to be reactive rather than strategic, adaptive rather than interventionist, in overcoming agricultural threats' (ibid.: 465). Indeed, he continues, farmers in Timor appear 'adept at accommodating the exotic weedy visitor and adjusting their farming systems to the constraints and advantages it offers' (ibid.: 467). From a long-term perspective, the weedy 'plagues' appear to resolve themselves.

A political ecological scope of landscape transformation provides a better sense of the varied ways in which plants' biophysical agency and human activity, intentionality and control come together to transform landscapes and rework social relations than a scope of ecological and social disruptions of place. Weeds do not act alone; invasives are not inherently bad organisms. Humans and weeds go together; plants take advantage of spaces and opportunities that we create. Human desires for preserving certain social values in landscapes in contradiction to actual transformations are often at the heart of definitions of and conflicts over weeds or invasives. A political ecology of landscape transformation allows us to see how these interactions and contradictions between humans, domesticates and weeds play out over time.

\section{REFERENCES}

Atchison, J. and L. Head (2013), 'Eradicating bodies in invasive plant management', Environment and Planning D, 31, 951-68.

Awanyo, L. (2001), 'Labor, ecology, and a failed agenda of market incentives: the political ecology of agrarian reforms in Ghana', Annals of the Association of American Geographers, 91, 92-121.

Barker, K. (2008), 'Flexible boundaries in biosecurity: accomodating gorse in Aotearoa New Zealand', Environment and Planning A, 40, 1598-614.

Bingham, N., G. Enticott and S. Hinchliffe (2008), 'Biosecurity: spaces, practices, and boundaries', Environment and Planning A, 40, 1528-33.

Blackburn, T.M., P. Pyšek, S. Bacher, J.T. Carlton, R.P. Duncan, V. Jarošík, J.R.U. Wilson and D.M. Richardson (2011), 'A proposed unified framework for biological invasions', Trends in Ecology \& Evolution, 26, 333-9.

Botkin, D. (2012), The Moon in the Nautilus Shell, Oxford: Oxford University Press.

Brandes, D. and J. Nitzche (2006), 'Biology, introduction, dispersal, and distribution of 
common ragweed (Ambrosia artemisiifolia L.) with special regard to Germany', Nachrichtenblatt des Deutschen Pflanzenschutzdienstes [Communications from the German Plant Protection Services], 58, 286-91.

Braun, B. (2011), 'Governing disorder: biopolitics and the molecularization of life', in R. Peet, P. Robbins and M. Watts (eds), Global Political Ecology, London: Routledge, pp. 389-411.

Brockway, L.H. (1979), Science and Colonial Expansion, New York: Academic Press.

Brown, J.H. and D.F. Sax (2004), 'An essay on some topics concerning invasive species', Austral Ecology, 29, 530-36.

Chauvel, B., F. Dessaint, C. Cardinal-Legrand and F. Bretagnolle (2006), 'The historical spread of Ambrosia artemisiifolia L. in France from herbarium records', Journal of Biogeography, 33, 665-73.

Colautti, R.I. and H.J. MacIsaac (2004), "A neutral terminology to define "invasive" species', Diversity and Distributions, 10, 135-41.

Cosgrove, D. (1998), Social Formation and Symbolic Landscape, Madison, WI: University of Wisconsin Press.

Cronk, Q.C.B. and J.L. Fuller (1995), Plant Invaders, London: Chapman \& Hall.

Crosby, A. (1986), Ecological Imperialism, Cambridge: Cambridge University Press.

Davis, M.A. (2009), Invasion Biology, Oxford: Oxford University Press.

Dobson, A., K. Barker and S.L. Taylor (eds) (2013), Biosecurity, London: Routledge.

Drake, J.A., H.A. Mooney, F. di Castri, R.H. Groves, F.J. Kruger, M. Rejmánek and M. Williamson (eds) (1989), Biological Invasions, Chichester, UK: John Wiley \& Sons.

Elden, S. (2007), 'Governmentality, calculation, territory', Environment and Planning $D, 25,562-80$.

Elton, C. (1958, reprinted 2000), The Ecology of Invasion by Animals and Plants, Chicago, IL: University of Chicago Press.

Fall, J.J. (2013), 'Biosecurity and ecology: beyond the nativism debate', in A. Dobson, K. Barker and S.L. Taylor (eds), Biosecurity, London: Routledge, pp. 165-79.

Foucault, M. (1980), 'Truth and power', in C. Gordon (ed.), Power/Knowledge, New York: Pantheon, pp. 109-33.

Gould, S.J. (1997), 'An evolutionary perspective on strengths, fallacies, and confusions in the concept of native plants', in J. Wolschke-Bulmahn (ed.), Nature and Ideology, Washington, DC: Dumbarton Oaks, pp. 11-19.

Gröning, G. and J. Wolschke-Bulmahn (2003), 'The native plant enthusiasm: ecological panacaea or xenophobia', Landscape Research, 28, 75-88.

Harlan, J.R. and J.M.J. de Wet (1965), 'Some thoughts about weeds', Economic Botany, 19, 16-24.

Head, L. and P. Muir (2004), 'Nativeness, invasiveness, and nation in Australian plants', Geographical Review, 94, 199-217.

Hobbs, R.J. and 17 others (2006), 'Novel ecosystems: theoretical and management aspects of the new ecological world order', Global Ecology and Biogeography, $15,1-7$.

Holm, L.G., D.L. Plucknett, J.V. Pancho and J.P. Herberger (1977), The World's Worst Weeds, Honolulu, HI: University of Hawaii Press.

Humair, F., P.J. Edwards, M. Siegrist and C. Kueffer (2014), 'Understanding misunderstandings in invasion science: why experts don't agree on common concepts and risk assessments', NeoBiota, 20, 1-30. 
Kannan, R., C.M. Shackleton and R. Uma Shaanker (2013), 'Reconstructing the history of introduction and spread of the invasive species, Lantana, at three spatial scales in India', Biological Invasions, 15, 1287-302.

Kondo, T., M.D. Crisp, C. Linde, D.M.J.S. Bowman, K. Kawamura, S. Kaneko and Y. Isagi (2012), 'Not an ancient relic: the endemic Livistona palms of arid central Australia could have been introduced by humans', Proceedings B, of the Royal Society, 279, 2652-61.

Kull, C.A. and H. Rangan (2008), 'Acacia exchanges: wattles, thorn trees, and the study of plant movements', Geoforum, 39, 1258-72.

Kull, C.A., S.M. Carriere, S. Moreau, H. Rakoto Ramiarantsoa, C. Blanc-Pamard and J. Tassin (2013), 'Melting pots of biodiversity: tropical smallholder farm landscapes as guarantors of sustainability', Environment, 55, 6-15.

Larson, B.M.H. (2011), Metaphors for Environmental Sustainability, New Haven, CT: Yale University Press.

Lefebvre, H. (1974 [transl. 1991]), The Production of Space, Oxford: Blackwell.

Marris, E. (2011), Rambunctious Garden, New York: Bloomsbury.

McKinney M.L. and J.L. Lockwood (1999), 'Biotic homogenization: a few winners replacing many losers in the next mass extinction', Trends in Ecology and Evolution, 14, 450-53

McNeill, J.R. (2003), 'Europe's place in the global history of biological exchange', Landscape Research, 28, 33-9.

McWilliam, A. (2000), 'A plague on your house? Some impacts of Chromolaena odorata on Timorese livelihoods', Human Ecology, 28, 451-69.

MEA (Millennium Ecosystem Assessment) (2005), Ecosystems and Human Well-being, Washington, DC: Island Press.

Middleton, K. (2012), 'Renarrating a biological invasion: historical memory, local communities and ecologists', Environment and History, 18, 61-95.

Mitman, G. (2004), 'When pollen became poison: a cultural geography of ragweed in America', in L. Daston and F. Vidal (eds), Moral Authority of Nature, Chicago, IL: University of Chicago Press, pp. 438-65.

Neely, A.H. (2010), 'Blame it on the weeds: politics, poverty, and ecology in the New South Africa', Journal of Southern African Studies, 36, 869-87.

Osborne, M.A. (2000), 'Acclimatizing the world: a history of the paradigmatic colonial science', Osiris, 2nd series, 15, 135-51.

Pejchar, L. and H.A. Mooney (2009), 'Invasive species, ecosystem services and human well-being', Trends in Ecology and Evolution, 24, 497-504.

Pimentel, D., R. Zuniga and D. Morrison (2005), 'Update on the environmental and economic costs associated with alien-invasive species in the United States', Ecological Economics, 52, 273-88.

Rabinow, P. and N. Rose (2006), 'Biopower today', BioSocieties, 1, 195-217.

Rangan, H. and C.A. Kull (2009), 'What makes ecology "political"? Rethinking "scale" in political ecology', Progress in Human Geography, 33, 28-45.

Rangan, H., A. Wilson and C.A. Kull (2014), 'Thorny problems: industrial pastoralism and managing "country" in Northwest Queensland', in J. Frawley and I. McCalman (eds), Rethinking Invasion Ecologies from the Environmental Humanities, London: Routledge, pp. 116-34.

Rangan, H., J. Carney and T. Denham (2012), 'Environmental history of botanical exchanges in the Indian Ocean World', Environment and History, 18, 311-42.

Rangan, H., K.L. Bell, D.A. Baum, R. Fowler, P. McConvell, T. Saunders, S. Spronck, C.A. Kull and D.J. Murphy (2015), 'New genetic and linguistic analyses show 
ancient human influence on baobab evolution and distribution in Australia', PLoS ONE, 10, e0119758, doi: 10.1371/journal.pone.0119758.

Richardson, D.M. (ed.) (2011), Fifty Years of Invasion Ecology, Oxford: WileyBlackwell.

Richardson, D.M., P. Pyšek, D. Simberloff, M. Rejmánek and A.D. Mader (2008), 'Biological invasions - the widening debate: a response to Charles Warren', Progress in Human Geography, 32, 295-8.

Richardson, D.M., J. Carruthers, C. Hui, F.A.C. Impson, J.T. Miller, M.P. Robertson, M. Rouget, J.J. Le Roux and J.R.U. Wilson (2011), 'Human-mediated introductions of Australian Acacia species - a global experiment in biogeography', Diversity and Distributions, 17, 771-87.

Robbins, P. (2007), Lawn People, Philadelphia, PA: Temple University Press.

Sauer, C.O. (1969), Agricultural Origins and Dispersals, 2nd edn, Cambridge, MA: MIT Press.

Schaefer, H., M.A. Carine, and F.J. Rumsey (2011), 'From European priority species to invasive weed: Marsilea azorica (Marsileaceae) is a misidentified alien', Systematic Biology, 36, 845-53.

Seddon, G. (2005), The Old Country, Cambridge: Cambridge University Press.

Starfinger, U., I. Kowarik, M. Rode and H. Schepker (2003), 'From desirable ornamental plant to pest to accepted addition to the flora? The perception of an alien tree species through the centuries', Biological Invasions, 5, 323-35.

Tassin, J. and C.A. Kull (2012), 'Pour une autre représentation métaphorique des invasions biologiques' [Devising other metaphors for biological invasions], Natures Sciences Sociétés, 20, 404-14.

Thaman, R.R. (1974), 'Lantana camara: its introduction, dispersal and impact on islands of the tropical Pacific Ocean', Micronesica, 10, 17-39.

Tilman, D., J. Fargione, B. Wolff, C. D’Antonio, A. Dobson, R. Howarth, D. Schindler, W.H. Schlesinger, D. Simberloff and D. Swackhamer (2001), 'Forecasting agriculturally driven global environmental change', Science, 292, 281-4.

Timmons, F.L. (1970), 'A history of weed control in the United States and Canada', Weed Science, 18, 294-307.

Tyrrell, I. (1999), True Garden of the Gods, Berkeley, CA: University of California Press

Vitousek, P.M., C.M. D’Antonio, L.L. Loope, M. Rejmánek and R. Westbrooks (1997), 'Introduced species: a significant component of human-caused change', New Zealand Journal of Ecology, 21, 1-16.

Warren, C.R. (2007), 'Perspectives on the "alien" versus "native" species debate: a critique of concepts, language and practice', Progress in Human Geography, 31, 427-46.

Wilson, J.R.U., E.E. Dormontt, P.J. Prentis, A.J. Lowe and D.M. Richardson (2009), 'Something in the way you move: dispersal pathways affect invasion success', Trends in Ecology and Evolution, 24, 136-44.

Zimdahl, R. (2010), A History of Weed Science in the United States, London: Elsevier. 